\title{
Early and midterm outcomes of hemiarch replacement combined with stented elephant trunk in the management of acute DeBakey type I aortic dissection: Comparison with total arch replacement
}

\author{
Enyi Shi, MD, PhD, Tianxiang Gu, MD, PhD, Yang Yu, MD, Lei Yu, MD, Chun Wang, MD, PhD, \\ Qin Fang, MD, and Yuhai Zhang, MD, PhD
}

\begin{abstract}
Objective: For patients with acute DeBakey type I aortic dissection without an intimal tear in the arch, the early and midterm outcomes of hemiarch replacement with stented elephant trunk were compared with those of total arch replacement.
\end{abstract}

\begin{abstract}
Methods: From January 2006 to December 2011, 197 patients with acute type I aortic dissection were identified without an intimal tear in the arch. Of the 197 patients, 71 underwent hemiarch replacement with stented elephant trunk implantation (hemiarch group) and 84 underwent ascending aorta and total arch replacement with stented elephant trunk implantation (total arch group).
\end{abstract}

\begin{abstract}
Results: The incidence of postoperative transient neurologic dysfunction, low cardiac output syndrome, and prolonged ventilation was lower in the hemiarch group $(P<.05$ for all $)$. The hospital mortality was $4.2 \%$ and $5.9 \%$ for the hemiarch and total arch groups, respectively $(P=.91)$. No difference was detected in survival between the 2 groups $(P=.56)$. Complete thrombosis in the false lumen of the residual arch was found in $92.1 \%$ of those undergoing hemiarch replacement. The rate of complete thrombosis in the false lumen of the distal aorta was similar between the 2 groups $(P>.05)$. The risk of an aortic event was similar for both groups $(P=.62)$.

Conclusions: For patients with acute DeBakey type I dissection without an intimal tear in the arch, hemiarch replacement with stented elephant trunk implantation was easily performed, with satisfactory early and midterm outcomes. For these selective patients, total arch replacement with the stented elephant trunk technique did not improve the late surgical results further. (J Thorac Cardiovasc Surg 2014;148:2125-31)
\end{abstract}

Acute aortic dissections of DeBakey type I conjointly affect the ascending aorta, arch, and more distal aorta. The optimal surgical strategy for type I dissections has spanned the more conservative approaches of using only replacement of the ascending aorta or hemiarch with or without resection of the intimal tear to more aggressive methods of total replacement of the ascending aorta and aortic arch combined with the elephant trunk technique..$^{1-7}$ Ascending aorta or hemiarch replacement is believed to be sufficient for saving the patient's life. ${ }^{5-7}$ However, the untreated false lumen of the distal aorta can expose the patients to the risk of aortic rupture or repeat intervention. ${ }^{8,9}$ Replacement of the ascending aorta and total arch combined with the elephant trunk technique has been recommended for type I aortic dissections by some investigators because of the satisfactory long-term

\footnotetext{
From the Department of Cardiac Surgery, First Affiliated Hospital, China Medical University, Shenyang, China.

Disclosures: Authors have nothing to disclose with regard to commercial support.

Received for publication Aug 23, 2013; revisions received Oct 1, 2013; accepted for publication Oct 27, 2013; available ahead of print Dec 2, 2013.

Address for reprints: Tianxiang Gu, MD, PhD, Department of Cardiac Surgery,

First Affiliated Hospital, China Medical University, Shenyang 110001, People's

Republic of China (E-mail: cmugtx@sina.com).

$0022-5223 / \$ 36.00$

Copyright (c) 2014 by The American Association for Thoracic Surgery

http://dx.doi.org/10.1016/j.jtcvs.2013.10.058
}

results. ${ }^{1,2}$ However, the complicated procedure of total arch replacement is still a great challenge to cardiac surgeons.

Resection or sealing of the intimal tear is 1 of the principles for surgical treatment of acute aortic dissections. Of those with type I aortic dissection, only $10 \%$ to $30 \%$ of patients will have intimal tears in the arch. ${ }^{10-12}$ For patients with type I dissection without a tear in the arch, hemiarch replacement combined with stented elephant trunk implantation, a more simplified procedure, was performed at our institute. ${ }^{3}$ In the present retrospective study, the early and midterm results of hemiarch replacement combined with stented elephant trunk implantation for type I dissections were evaluated by comparing the results with those of total arch replacement with stented elephant trunk implantation in patients treated during the same period.

\section{METHODS \\ Patients}

From January 2006 to December 2011, 234 patients with acute DeBakey type I aortic dissection underwent surgical treatment in our department. Of the 234 patients, $197(84.2 \%)$ were identified without an intimal tear in the arch using preoperative computed tomographic angiography and direct intraoperative inspection. Of the 197 patients, 71 underwent ascending aorta and hemiarch replacement combined with stented elephant trunk implantation (hemiarch group) and 84 underwent 


\section{Abbreviations and Acronyms \\ $\mathrm{CPB}=$ cardiopulmonary bypass \\ $\mathrm{SCP}=$ selective antegrade cerebral perfusion}

ascending aorta and total arch replacement combined with stented elephant trunk implantation (total arch group). The operative procedure of hemiarch replacement or total arch replacement was finally selected at the surgeon's discretion according to the patient's condition. All the surgeries were performed by the same surgeon (T.G.). The ethics committee of the First Affiliated Hospital, China Medical University, approved the present study. The demographic and preoperative data of the patients are listed in Table 1.

\section{Surgical Technique}

A median sternotomy was performed with the upper end of the incision higher. Cannulation of the innominate artery $^{3}$ or right axillary artery was performed for cardiopulmonary bypass (CPB). Venous return was established using a 2-stage cannula introduced by way of the right atrium. When the patient had cooled to $32^{\circ} \mathrm{C}$, the aorta was clamped just proximal to the innominate artery. Then, the ascending aorta was opened longitudinally. The cardioplegic solution was perfused antegradely. After a careful inspection of the aortic valve and coronary ostia, a decision was made regarding the subsequent root procedure. Supracommissural aortic replacement was performed with suitable vessel prosthesis whenever the root was not involved in the dissection and no aortic insufficiency was present. If the aortic regurgitation was severe, the Bentall, Wheat, or David procedure was performed according to whether the coronary ostia were affected by the dissection. During this period, the body temperature was continually decreased. Once the root procedure was accomplished after reaching hypothermic circulatory arrest with an anticipated rectal temperature of about $25^{\circ} \mathrm{C}$, the circulation was arrested. Next, selective antegrade cerebral perfusion (SCP) was performed at a rate of 8 to $10 \mathrm{~mL} / \mathrm{kg} / \mathrm{min}$.

For patients undergoing hemiarch replacement, the arch was transected obliquely, with removal of most of the small curvature of the arch. A self-expandable stent vessel prosthesis (MicroPort Medical, Co, Ltd, Shanghai, China) was inserted into the true lumen of the descending aorta. The proximal end of the stent vessel prosthesis was positioned just distal to the origin of the left subclavian artery. A continuous suture (4-0 Prolene suture) was performed inside the residual arch and ran through the entire native vessel wall to fix the stented vessel to the aorta. The distal anastomosis of the vessel prosthesis and the preserved native arch was accomplished with a continuous suture using an open aortic technique. The detailed procedure has been described in our previous report. ${ }^{3}$

For patients undergoing total arch replacement, the ascending aorta and transverse arch were opened. The distal aorta was transected circumferentially close to the proximal margin of the origin of the left subclavian artery. The same stent vessel prosthesis used in the patients undergoing hemiarch replacement was then inserted into the true lumen of the descending aorta. The anastomosis between the 4-branched prosthetic graft and the distal aorta containing the intraluminal stented graft was performed using the open aortic technique. After the anastomosis was completed, blood perfusion of the lower body was started by the perfusion limb of the 4-branched prosthetic graft. During rewarming, the left subclavian artery, left common carotid artery, and innominate artery were anastomosed to the respective limbs of the 4-branched prosthetic graft in an end-to-end style.

\section{Neurologic Dysfunction Evaluation}

Permanent neurologic dysfunction was defined as stroke confirmed using conventional imaging techniques. Temporary neurologic dysfunction was defined as a subtle, but diffused, brain injury and was classified into 5 grades $^{13}$ (Table 2). The neuropsychological evaluation was performed of each patient by a neurologist postoperatively.

\section{Follow-up}

The follow-up data were obtained by clinical interviews or telephone interviews conducted according to a standardized questionnaire. Computed tomographic angiography was performed before discharge, 3 months after surgery, and every 6 months thereafter. The endpoints of the study were death, an aortic event, defined as reintervention for the residual aortic pathologic features, or distal aortic dilatation with a maximal diameter of $>55 \mathrm{~mm}$.

\section{Statistical Analysis}

The categorical variables are presented as percentages and were analyzed using the $\chi^{2}$ test. The continuous variables are expressed as the mean \pm standard deviation and were analyzed using the Student $t$ test. Statistical analysis of the neurologic scores was performed using the Mann-Whitney $U$ test. The actuarial survival and freedom from aortic events were calculated using the Kaplan-Meier method, followed by the log-rank test.

\section{RESULTS}

\section{Intra- and Postoperative Profiles}

The intra- and postoperative variables of the 2 groups are listed in Table 3. No significant differences in the aortic root procedures and concomitant surgeries were found between the 2 groups $(P>.05)$. The CPB, crossclamping, and SCP durations were significantly shorter in the hemiarch group than in the total arch group $(P<.01)$. No significant differences were found in the duration of hypothermic circulatory arrest or the lowest rectal temperature between the 2 groups $(P>.05)$. No permanent neurologic dysfunction, paraplegia, or paralysis occurred in the whole cohort. No marked differences were seen in the incidence of reoperation for bleeding, dialysis, or sepsis between the 2 groups $(P>.05)$. The rate of low cardiac output syndrome and prolonged ventilation in the hemiarch group was lower than that in the total arch group $(P=.03)$. The incidence of temporary neurologic dysfunction was significantly lower in the hemiarch group than in the total arch group $(P=.04)$. A total of 8 hospital deaths $(5.2 \%)$ occurred in the whole cohort, with no significant difference between the 2 groups $(P=.91)$.

\section{Midterm Results}

A total of 147 patients were discharged; 11 patients in the total arch group and 7 in the hemiarch group were lost during follow-up. The average follow-up period was $42.7 \pm 17.8$ months for the hemiarch group and $50.4 \pm 20.0$ months for the total arch group $(P=.36)$. One patient died of rupture of the abdominal aortic aneurysm 13 months after total arch replacement. The other deaths were attributed to nonaortic causes (Table 4). One patient undergoing hemiarch replacement was detected to have a small endoleak from the proximal end of the stent 
TABLE 1. Demographic and preoperative data

\begin{tabular}{lccr}
\hline \multicolumn{1}{c}{ Variable } & $\begin{array}{c}\text { Hemiarch } \\
(\mathbf{n}=\mathbf{7 1})\end{array}$ & $\begin{array}{c}\text { Total arch } \\
(\mathbf{n = 8 4 )}\end{array}$ & $\begin{array}{c}\boldsymbol{P} \\
\text { value }\end{array}$ \\
\hline Male gender & $53(74.6)$ & $57(67.9)$ & .35 \\
Age (y) & $55.9 \pm 10.1$ & $53.9 \pm 12.2$ & .28 \\
Marfan syndrome & $10(14.1)$ & $22(26.2)$ & .06 \\
Preoperative comorbidities & & & \\
$\quad$ Hypertension & $55(77.5)$ & $67(79.8)$ & .73 \\
Hyperlipidemia & $16(22.5)$ & $23(27.4)$ & .49 \\
Diabetes & $12(16.9)$ & $19(22.6)$ & .38 \\
History of CVA & $2(2.8)$ & $2(2.4)$ & 1.00 \\
$\quad$ Hypoxemia & $17(23.9)$ & $21(25.0)$ & .88 \\
Renal failure & $5(7.0)$ & $4(4.8)$ & .80 \\
$\quad$ creatine $>$ 2.0 mg/dL) & & & \\
Tamponade & $13(18.3)$ & $12(14.3)$ & .50 \\
Coronary heart disease & $7(9.9)$ & $6(7.1)$ & .54 \\
Aortic regurgitation & & & \\
$\quad$ Moderate & $11(15.5)$ & $9(10.7)$ & .38 \\
Severe & $13(18.3)$ & $15(17.9)$ & .94 \\
\hline
\end{tabular}

Data presented as $\mathrm{n}(\%)$ or mean \pm standard deviation. CVA, Cerebrovascular accident.

vessel prosthesis before discharge. At 24 months postoperatively, the endoleak seemed to have decreased. No secondary intervention was performed, and the patient was followed up closely. The overall survival (excluding the hospital deaths) of the whole cohort was $100 \%$, $90.6 \%$, and $88.3 \%$ at 1,3 , and 5 years, respectively (Figure 1). Figure 2 demonstrates the survival function of the 2 groups, and no significant difference was detected $(P=.56)$.

For the hemiarch group, the false lumen at the arch was decreased, with complete thrombosis formation, in $88.2 \%, 90.8 \%, 92.1 \%$, and $92.5 \%$ of the patients before discharge and 6,12 , and 24 months postoperatively, respectively (Table 5). No significant dilation of the residual arch was found, including in the patients with Marfan syndrome. No reintervention was performed because of a residual native arch during follow-up. The behavior of the false lumen of the descending aorta for the whole cohort is listed in Table 5. The rate of complete thrombosis formation at the different levels of the distal aorta in the 2 groups was similar at the different follow-up points $(P>.05)$. For patients with only partial thrombosis formation or without thrombosis in the false lumen of the descending aorta, no reintervention was recommended if

TABLE 2. Clinical scale for temporary neurologic dysfunction

\begin{tabular}{lll}
\hline Grade & \multicolumn{1}{c}{ Description } & \multicolumn{1}{c}{ Duration } \\
\hline 0 & Normal & \\
1 & Simple confusion & Short $(<48 \mathrm{~h})$ \\
2 & Confusion and lethargy & Short \\
3 & Confusion and agitation & Short $(<72 \mathrm{~h})$ \\
4 & Overt psychosis & Long $(>72 \mathrm{~h})$ \\
5 & Psychosis, parkinsonism & Long \\
\hline
\end{tabular}

no enlargement was found in the false lumen during close follow-up. Enlargement of the descending aorta $(>55 \mathrm{~mm})$ was detected in 8 patients (4 patients in each group). Two patients underwent endovascular abdominal aortic repair and were discharged without sequelae. The other patients refused reoperation for personal reasons and were followed up closely. The 5-year freedom from aortic events was $88.8 \%$ in the hemiarch group and $91.3 \%$ in the total arch group $(P=.62$; Figure 3$)$.

\section{DISCUSSION}

Acute DeBakey type I aortic dissection is the most lethal disease of the aorta, with high morbidity and mortality. Surgical treatment has been recommended to prevent aortic rupture, avoid or correct aortic valve insufficiency, and restore flow to the compromised branch vessels. Complete resection of the intimal tear and reapproximation of the proximal and distal edges of the dissected aorta have been the primary objectives of surgery. ${ }^{14}$ For patients with an intimal tear in the arch, total arch replacement will be necessary to eliminate the intimal tear. However, an intimal tear in the arch has only been detected in less than one third of patients with type I dissections. ${ }^{10-12,15}$ In our department, $15.8 \%$ of 234 type I dissections were identified with a tear in the arch. Hemiarch replacement can eliminate intimal tears in the ascending aorta or small curvature of the arch. Thus, for most type I dissections without a tear in the arch, the optimal surgical strategy is still under debate.

Replacement of the ascending aorta or hemiarch with resection of the intimal tear might be the simplest, shortest, and safest surgical procedure for type I aortic dissections. The false lumen of the distal aorta will thrombose when blood perfusion has been interrupted after ascending aorta or hemiarch replacement. However, a patent false lumen at the arch and proximal descending aorta was found in $50 \%$ and $70 \%$ of the patients with type I dissection after proximal replacement. ${ }^{15}$ Dilatation of the residual aorta or the patent false lumen has been the main reason for reintervention after proximal replacement. Although some reports have indicated that the rate of aortic reoperation or aortic dilatation was not significantly different between hemiarch replacement and total arch replacement without an elephant trunk into the descending aorta, ${ }^{4,6,7}$ more surgeons have believed that total arch replacement, the more complex and extensive surgery for type I acute dissection, would decrease the rate of reoperation. ${ }^{16}$ The residual patent false lumen in the descending aorta has been recognized in approximately $30 \%$ of patients after total arch replacement, and $13 \%$ to $25 \%$ of patients with a residual patent false lumen required another operation within 5 years. ${ }^{17,18}$ To further improve the late surgical outcome, surgeons have recently switched from limited replacement of the ascending aorta or hemiarch to simultaneous replacement of the ascending aorta and 
TABLE 3. Surgical procedure and intraoperative and postoperative data

\begin{tabular}{lccc}
\hline \multicolumn{1}{c}{ Variable } & $\begin{array}{c}\text { Hemiarch } \\
(\mathbf{n}=\mathbf{7 1})\end{array}$ & $\begin{array}{c}\text { Total arch } \\
(\mathbf{n}=\mathbf{8 4})\end{array}$ & $\begin{array}{c}\boldsymbol{P} \\
\text { value }\end{array}$ \\
\hline Aortic root surgery & & & \\
$\quad$ Bentall procedure & $15(21.1)$ & $17(20.2)$ & .89 \\
$\quad$ Wheat procedure & $7(9.9)$ & $6(7.1)$ & .54 \\
$\quad$ David procedure & $2(2.8)$ & $1(1.2)$ & .88 \\
Concomitant procedures & & & \\
MV repair/replacement & $4(5.6)$ & $5(6.0)$ & 1.00 \\
CABG & $7(9.9)$ & $6(7.1)$ & .54 \\
CPB time (min) & $103.6 \pm 20.9$ & $164.7 \pm 19.6$ & $.00^{*}$ \\
Crossclamp time (min) & $75.7 \pm 15.7$ & $108.9 \pm 18.4$ & $.00^{*}$ \\
HCA time (min) & $30.6 \pm 4.9$ & $29.3 \pm 4.3$ & .07 \\
SCP time (min) & $30.6 \pm 4.9$ & $55.2 \pm 6.2$ & $.00^{*}$ \\
Lowest rectal temperature $\left({ }^{\circ} \mathrm{C}\right)$ & $23.3 \pm 1.6$ & $23.7 \pm 1.1$ & .06 \\
Reoperation for hemostasis & $2(2.8)$ & $1(1.2)$ & .88 \\
Ventilation time $>72 \mathrm{~h}$ & $5(7.0)$ & $16(19.0)$ & $.03^{*}$ \\
LCOS & $4(5.6)$ & $14(16.7)$ & $.03^{*}$ \\
Dialysis & $4(5.6)$ & $7(8.3)$ & .51 \\
Temporary neurologic dysfunction & & & $.04 *$ \\
$\quad$ Grade 1 & 8 & 14 & \\
Grade 2 & 3 & 9 & \\
Grade 3 & 1 & 3 & \\
Permanent neurologic dysfunction & 0 & 0 & \\
Paraplegia or paralysis & 0 & 0 & \\
Infection or sepsis & $3(4.2)$ & $3(3.6)$ & 1.00 \\
Hospital mortality & $3(4.2)$ & $5(5.9)$ & .91 \\
\hline
\end{tabular}

$M V$, Mitral valve; $C A B G$, coronary artery bypass grafting; $C P B$, cardiopulmonary bypass; $H C A$, hypothermia circulatory arrest; $S C P$, selective antegrade cerebral perfusion; $L C O S$, low cardiac output syndrome. ${ }^{*} P<.05$.

total arch combined with stented elephant trunk implantation into the distal aorta. ${ }^{1,14,15,19}$ Total arch repair has been thought to be associated with greater morbidity and mortality than hemiarch repair for acute DeBakey type I aortic dissection., ${ }^{4,6,7}$ With advances in surgical techniques, anesthesia, organ protection, and perioperative care, the safety of total arch replacement has increased significantly. ${ }^{1,14,19}$ In recent reports, similar mortality and morbidity were found between those undergoing proximal arch replacement and total arch replacement. ${ }^{15,20,21}$ However, total arch replacement is still a highly invasive and risky procedure for patients with acute type I aortic

TABLE 4. Late death

\begin{tabular}{lcc}
\hline \multicolumn{1}{c}{ Cause } & Hemiarch $(\mathbf{n})$ & Total $\operatorname{arch}(\mathbf{n})$ \\
\hline Aortic-related death & 0 & 1 \\
Acute cardiac infarction & 1 & 1 \\
Renal failure & 1 & 2 \\
Stroke & 0 & 1 \\
Cerebral hemorrhage & 1 & 1 \\
Sepsis & 0 & 1 \\
Cancer & 0 & 1 \\
Pneumonia & 1 & 0 \\
Sudden death & 1 & 1 \\
\hline
\end{tabular}

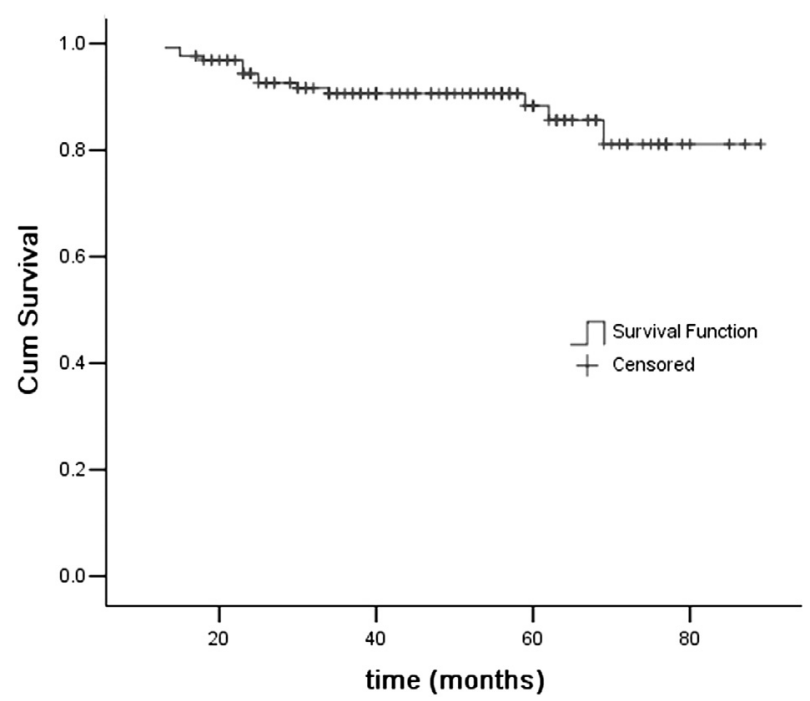

FIGURE 1. Overall survival of patients with acute DeBakey type I aortic dissection for the whole cohort. Cum, Cumulative.

dissection, mainly because it requires elaborate anastomoses of 3 arch vessels to the arch graft separately or reimplantation of the branches as an island flap into the arch graft. Anastomosis of the graft to the distal descending aorta will usually be very difficult because of the deep surgical field and can cause phrenic and recurrent laryngeal nerve injury.

In the present study, hemiarch replacement was combined with the stented elephant trunk technique for type I dissections without a tear in the arch. The early and midterm results of such a strategy were compared with those for total arch replacement with the stented elephant

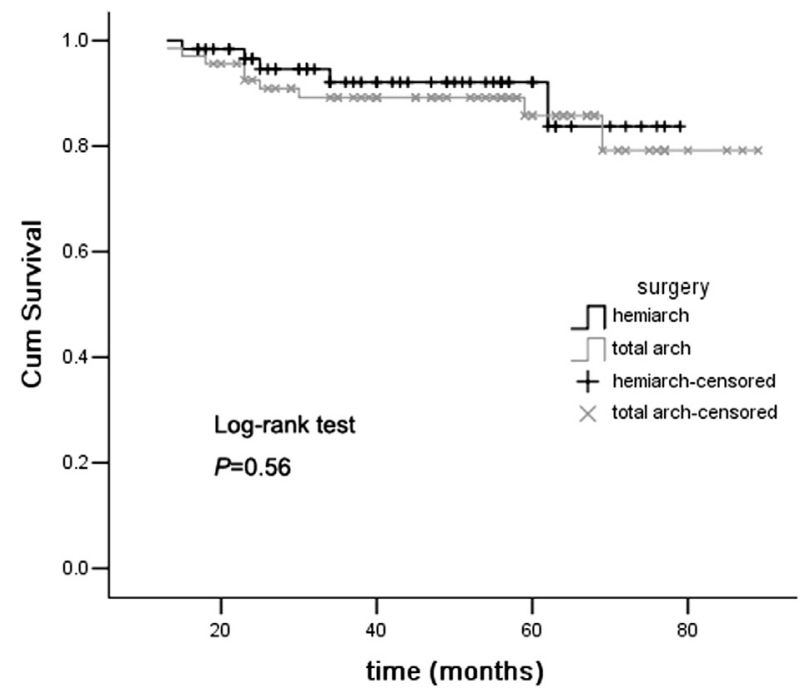

FIGURE 2. Survival of patients with acute DeBakey type I aortic dissection stratified by group (hemiarch vs total arch) during follow-up. No significant difference was found in survival between the 2 groups $(P=.56)$. Cum, Cumulative. 
TABLE 5. Complete thrombosis in false lumen of residual arch and descending aorta

\begin{tabular}{|c|c|c|c|c|c|c|c|c|c|c|c|c|}
\hline \multirow[b]{2}{*}{ Variable } & \multicolumn{3}{|c|}{ Before discharge } & \multicolumn{3}{|c|}{6 mo after surgery } & \multicolumn{3}{|c|}{12 mo after surgery } & \multicolumn{3}{|c|}{24 mo after surgery } \\
\hline & $\begin{array}{c}\text { Hemiarch } \\
(n=68)\end{array}$ & $\begin{array}{c}\text { Total } \\
\operatorname{arch} \\
(\mathbf{n}=79)\end{array}$ & $\begin{array}{c}P \\
\text { value }\end{array}$ & $\begin{array}{c}\text { Hemiarch } \\
(\mathbf{n}=65)\end{array}$ & $\begin{array}{c}\text { Total } \\
\text { arch } \\
(n=74)\end{array}$ & $\begin{array}{c}P \\
\text { value }\end{array}$ & $\begin{array}{c}\text { Hemiarch } \\
(\mathbf{n}=63)\end{array}$ & $\begin{array}{c}\text { Total } \\
\operatorname{arch} \\
(\mathbf{n}=71)\end{array}$ & $\boldsymbol{P}$ & $\begin{array}{c}\text { Hemiarch } \\
(\mathbf{n}=\mathbf{5 3})\end{array}$ & $\begin{array}{c}\text { Total } \\
\text { arch } \\
(\mathbf{n}=\mathbf{6 0})\end{array}$ & $\begin{array}{c}P \\
\text { value }\end{array}$ \\
\hline At arch & $60(88.2)$ & - & & 59 (90.8) & - & & $58(92.1)$ & - & & 49 (92.5) & - & \\
\hline Around stent & $55(80.9)$ & $65(82.3)$ & .83 & $60(92.3)$ & $70(94.6)$ & .84 & $60(95.2)$ & $68(95.8)$ & 1.00 & $52(98.1)$ & $59(98.3)$ & 1.00 \\
\hline $\begin{array}{l}\text { Middle descending } \\
\text { aorta level }\end{array}$ & $26(38.2)$ & $26(32.9)$ & .50 & $26(40.0)$ & $33(44.6)$ & .58 & $31(49.2)$ & $39(54.9)$ & .51 & $28(52.8)$ & $35(58.3)$ & .56 \\
\hline Diaphragmatic level & $15(22.1)$ & $19(24.1)$ & .78 & $22(33.8)$ & $26(35.1)$ & .87 & $25(39.7)$ & $30(42.3)$ & .76 & $24(45.3)$ & $26(43.3)$ & .84 \\
\hline
\end{tabular}

Data presented as $\mathrm{n}(\%)$.

trunk technique in similar patients during the same period. In accordance with some newly published data, no significant differences in the in-hospital mortality were detected between the hemiarch and total arch groups. ${ }^{15,20,21}$ However, the surgical risks were decreased to some degree in the hemiarch group, as evidenced by the lower incidence of low cardiac output syndrome, prolonged ventilation, and transient neurologic dysfunction. The longer $\mathrm{CPB}$, crossclamping, and SCP periods inevitable with total arch surgery were directly related to cardiac and cerebral injury and organ dysfunction. In the present study, no permanent neurologic dysfunction was found. SCP, combined with hypothermic circulatory arrest, was used as a strategy for cerebral protection in the whole cohort, which might have contributed to the excellent outcomes of neurologic function in the present study. ${ }^{1-3,14,19}$

The survival rate of simple proximal replacement has been shown to be lower than that of total arch replacement with stented elephant trunk implantation. ${ }^{20,21}$ Total arch replacement might have eliminated the intimal tear in the

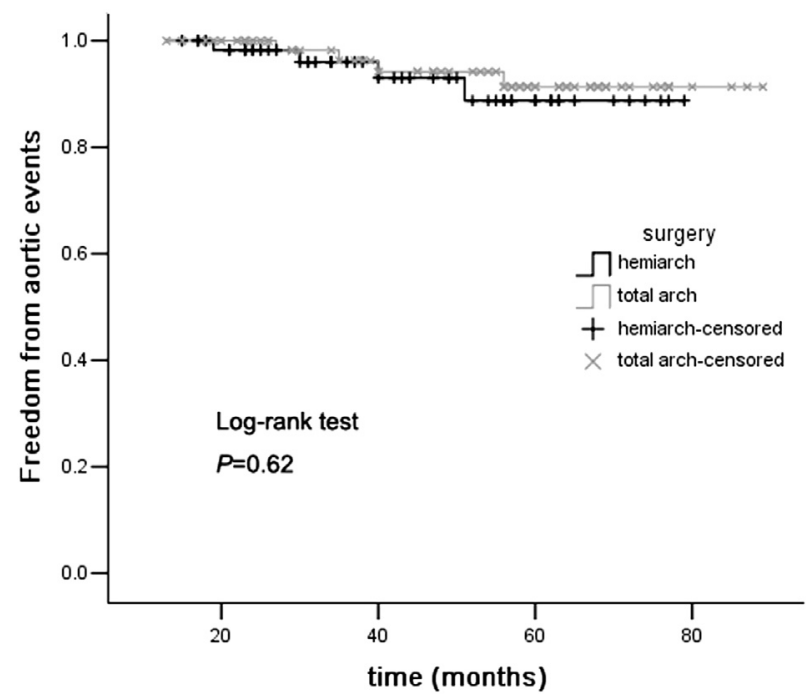

FIGURE 3. Freedom from aortic events for patients with acute DeBakey type I aortic dissection in the hemiarch and total arch groups during follow-up. The aortic event rate was not significantly different between the 2 groups $(P=.62)$. ascending aorta and arch, and the stented elephant trunk might seal the tear in the proximal descending aorta and improve thrombosis of the distal false lumen. This might explain the better long-term results of total arch replacement with the stented elephant trunk technique. ${ }^{1,14,19}$ In the present study, hemiarch replacement and total arch replacement were both combined with the stented elephant trunk technique using a similar type of stented graft. Regarding the thrombosis in the false lumen of the descending aorta, no significant differences were detected between the 2 groups during follow-up. The survival function of the hemiarch group and total arch group was comparable, and no significant differences were detected. The freedom from reintervention or significant dilatation of the distal aorta was also similar in both groups. Compared with the conventional elephant trunk technique, the stent can maintain the graft fully opened, fix the graft to the native aortic wall, seal the tear located at the distal aorta, compress the false lumen, and obliterate thrombus of the downstream false channel. ${ }^{19}$ In patients with extensive aneurysmal disease of the thoracic aorta, the elephant trunk and stented elephant trunk procedures seem to be associated with similar satisfactory early outcomes. The stented elephant trunk approach leads to single-stage treatment of all aortic disease in most patients and facilitates endovascular second-stage treatment in patients with residual distal thoracic aorta disease. The elephant trunk staged approach appears to leave a considerable percentage of patients at risk of adverse aortic events. $^{22}$ From the data published thus far, it seems justifiable to implant a stented elephant trunk in type I DeBakey dissections in centers with expertise in the treatment of aortic diseases. ${ }^{23}$ The difference in the surgical strategies between the 2 groups in the present study was that the great curvature and brachiocephalic arteries of the arch were preserved in patients undergoing hemiarch replacement. For type I dissections without intimal tears in the arch, hemiarch replacement still abides by the principle of complete resection of the intimal tear for treatment of type I dissection, although the partial arch was preserved. During follow-up, complete thrombosis in the false lumen of the residual arch was detected in 
$>90 \%$ of patients undergoing hemiarch replacement. Complete resection of the entire native arch tissue, which is prone to additional dilation, might be much more important for patients with Marfan syndrome, and total arch replacement using a branched graft to reconstruct the 3 branches of the arch has been recommended. ${ }^{24}$ In the present series, no significant dilatation was found in the residual arch in the hemiarch group during follow-up, including a few patients with Marfan syndrome. However, long-term follow-up is necessary to determine whether hemiarch replacement is as effective as total arch replacement with the reconstruction of the 3 branches of the arch separately in patients with Marfan syndrome. For hemiarch replacement combined with the stented elephant trunk technique, the proximal end of the stented graft was fixed to the native aorta using a continuous suture running through the entire native vessel wall prevent possible leakage. In the hemiarch group, only a slight endoleak was found in 1 patient, and no additional intervention was performed, except for close follow-up. Therefore, the present data have indicated that the stented elephant trunk technique can improve the late surgical outcome of ascending aorta and hemiarch replacement for patients with acute type I dissection without an intimal tear in the arch.

Spinal cord injury such as paraplegia and paralysis is a serious complication of stented elephant trunk implantation, with an incidence of $0 \%$ to $8 \%{ }^{1,3,14,15,20,24} \mathrm{~A}$ greater rate of spinal cord injury has occurred when extended grafts have been used. ${ }^{25}$ This might have resulted from extensive sacrifice of the intercostal arteries, jeopardizing collateral blood flow to the spinal cord, combined with imperfect protection during surgery. ${ }^{26}$ Therefore, the optimal length of the stented elephant trunk into the descending aorta is an important factor for avoiding spinal cord injury. No spinal cord injury occurred in the present study. Stented grafts no longer than $10 \mathrm{~cm}$ were used for the whole cohort. The intercostal arteries below the T8 level cannot be occluded using $10-\mathrm{cm}$ stented grafts. It must be emphasized that direct sizing through an incision in the aortic arch is very important for selecting the correct diameter of the stented graft.

As a much less invasive procedure, hybrid total arch repair using surgical debranching of the supra-aortic branches, followed by endovascular repair, has been reported in several studies, with satisfactory early and midterm outcomes. ${ }^{27-30}$ Reimplantation of the aortic arch vessels can be performed using a 4-branched graft sewn to the native ascending aorta just above the sinotubular junction without the aid of CPB. ${ }^{27-29}$ For this procedure, at least a part of the proximal ascending aorta must be normal for the landing zone of endovascular stent and the end to side anastomosis of the branched vessel graft. Therefore, most acute DeBakey type I dissections in which all of the ascending aorta has been affected by the dissection will not be appropriate for such a procedure. An alternative hybrid strategy would be to create a landing zone by replacement of the ascending aorta and reimplantation of the aortic arch vessels under CPB without deep hypothermia. ${ }^{29,30}$ Compared with conventional surgery, the complications of CPB or deep hypothermia can be decreased or avoided using the hybrid procedure. Hybrid arch repair might be indicated for patients with high risks for conventional surgery. ${ }^{27-30}$ However, the size of the published cohorts for hybrid total arch repair has been small, and no long-term results have been reported. The long-term outcomes of hybrid arch repair could be greatly influenced by the presence of postoperative type I endoleak, required reintervention, and the patency of the supra-aortic bypass. ${ }^{27}$ Although it has the potential to be an alternative to conventional surgery, hybrid arch repair cannot substitute for conventional surgical arch replacement in most patients with acute DeBakey type I dissections.

\section{Study Limitations}

The present retrospective study was not randomized. The nonrandomized design could have affected the results because of unmeasured confounders, procedure bias, or detection bias.

\section{CONCLUSIONS}

The present retrospective study has demonstrated that, for patients with acute DeBakey type I dissection without an intimal tear in the arch, hemiarch replacement combined with the stented elephant trunk technique can be easily performed with satisfactory early and midterm outcomes. For these selective patients, total arch replacement combined with the stented elephant trunk technique did not improve the late surgical results further.

\section{References}

1. Sun L, Qi R, Zhu J, Liu Y, Zheng J. Total arch replacement combined with stented elephant trunk implantation: a new "standard" therapy for type A dissection involving repair of the aortic arch? Circulation. 2011;123:971-8.

2. Kazui T, Yamashita K, Washiyama N, Terada H, Bashar AH, Suzuki K, et al. Aortic arch replacement using selective cerebral perfusion. Ann Thorac Surg. 2007;83:S796-8; discussion S824-31.

3. Shi E, Gu T, Yu L, Xiu Z, Zhang Z, Wang C, et al. Repair of Stanford type A aortic dissection with ascending aorta and hemiarch replacement combined with stent-graft elephant trunk technique by using innominate cannulation. J Thorac Cardiovasc Surg. 2011;142:1458-63.

4. Kim JB, Chung CH, Moon DH, Ha GJ, Lee TY, Jung SH, et al. Total arch repair versus hemiarch repair in the management of acute DeBakey type I aortic dissection. Eur J Cardiothorac Surg. 2011;40:881-7.

5. Ohtsubo S, Itoh T, Takarabe K, Rikitake K, Furukawa K, Suda H, et al. Surgical results of hemiarch replacement for acute type A dissection. Ann Thorac Surg. 2002;74:S1853-6.

6. Westaby S, Saito S, Katsumata T. Acute type A dissection: conservative methods provide consistently low mortality. Ann Thorac Surg. 2002;73:707-13.

7. Shiono M, Hata M, Sezai A, Niino T, Yagi S, Negishi N. Validity of a limited ascending and hemiarch replacement for acute type A aortic dissection. Ann Thorac Surg. 2006;82:1665-9. 
8. Zierer A, Voeller RK, Hill KE, Kouchoukos NT, Damiano RJ Jr, Moon MR. Aortic enlargement and late reoperation after repair of acute type A aortic dissection. Ann Thorac Surg. 2007;84:479-86.

9. Kirsch M, Legras A, Bruzzi M, Louis N. Fate of the distal aorta after surgical repair of acute DeBakey type I aortic dissection: a review. Arch Cardiovasc Dis. 2011;104:125-30.

10. Rehders TC, Ince $H$, Nienaber CA. Aortic dissection: from aetiology to therapeutic management. Medicine. 2006;34:296-301.

11. Takami Y, Tajima K, Kato W, Fujii K, Hibino M, Munakata H, et al. Can we predict the site of entry tear by computed tomography in patients with acute type A aortic dissection? Clin Cardiol. 2012;35:500-4.

12. Okita Y, Takamoto S, Ando M, Morota T, Yamaki F, Kawashima Y, et al. Surgery for aortic dissection with intimal tear in the transverse aortic arch. Eur J Cardiothorac Surg. 1996;10:784-90.

13. Ergin MA, Uysal S, Reich DL, Apaydin A, Lansman SL, McCullough JN, et al. Temporary neurological dysfunction after deep hypothermic circulatory arrest: a clinical marker of long-term functional deficit. Ann Thorac Surg. 1999;67: 1887-90.

14. Sun L, Qi R, Chang Q, Zhu J, Liu Y, Yu C, et al. Surgery for acute type A dissection using total arch replacement combined with stented elephant trunk implantation: Experience with 107 patients. J Thorac Cardiovasc Surg. 2009; 138:1358-62.

15. Zhang H, Lang X, Lu F, Song Z, Wang J, Han L, et al. Acute type A dissection without intimal tear in arch: proximal or extensive repair? J Thorac Cardiovasc Surg. Epub 2013 Jun 15.

16. Malvindi PG, van Putte BP, Sonker U, Heijmen RH, Schepens MA, Morshuis WJ. Reoperation after acute type a aortic dissection repair: a series of 104 patients. Ann Thorac Surg. 2013;95:922-7.

17. Ando M, Nakajima N, Adachi S, Nakaya M, Kawashima Y. Simultaneous graft replacement of the ascending aorta and total aortic arch for type A aortic dissection. Ann Thorac Surg. 1994;57:669-76.

18. Kazui T, Kimura N, Yamada O, Komatsu S. Total arch graft replacement in patients with acute type A aortic dissection. Ann Thorac Surg. 1994;58: 1462-8.

19. Liu ZG, Sun LZ, Chang Q, Zhu JM, Dong C, Yu CT, et al. Should the "elephant trunk" be skeletonized? Total arch replacement combined with stented elephant trunk implantation for Stanford type A aortic dissection. J Thorac Cardiovasc Surg. 2006;131:107-13.
20. Uchida N, Shibamura H, Katayama A, Shimada N, Sutoh M, Ishihara H Operative strategy for acute type A aortic dissection: ascending aortic or hemiarch versus total arch replacement with frozen elephant trunk. Ann Thorac Surg. 2009;87:773-7.

21. Easo J, Weigang E, Hölzl PP, Horst M, Hoffmann I, Blettner M, et al. Influence of operative strategy for the aortic arch in DeBakey type I aortic dissection: analysis of the German Registry for Acute Aortic Dissection Type A. J Thorac Cardiovasc Surg. 2012;144:617-23.

22. Di Eusanio M, Borger M, Petridis FD, Leontyev S, Pantaleo A, Moz M, et al Conventional versus frozen elephant trunk surgery for extensive disease of the thoracic aorta. J Cardiovasc Med (Hagerstown). Epub 2013 Jul 17.

23. Hagl C, Pichlmaier M, Khaladj N. Elephant trunks in aortic surgery: fresh and frozen. J Thorac Cardiovasc Surg. 2013;143(3 Suppl):S98-102.

24. Sun L, Li M, Zhu J, Liu Y, Chang Q, Zheng J, et al. Surgery for patients with Marfan syndrome with type A dissection involving the aortic arch using total arch replacement combined with stented elephant trunk implantation: the acute versus the chronic. J Thorac Cardiovasc Surg. 2011;142:e85-91.

25. Leontyev S, Borger MA, Etz CD, Moz M, Seeburger J, Bakhtiary F, et al. Experience with the conventional and frozen elephant trunk techniques: a single-centre study. Eur J Cardiothorac Surg. Epub 2013 May 20.

26. Nishi H, Mitsuno M, Tanaka H, Ryomoto M, Fukui S, Miyamoto Y. Spinal cord injury in patients undergoing total arch replacement: a cautionary note for use of the long elephant technique. J Thorac Cardiovasc Surg. 2011;142:1084-9.

27. Murashita T, Mastsuda H, Domae K, Iba Y, Tanaka H, Sasaki H, et al Less invasive surgical treatment for aortic arch aneurysms in high-risk patients: comparative study of hybrid thoracic endovascular aortic repair and conventional total arch replacement. J Thorac Cardiovasc Surg. 2012;143:1007-13.

28. Milewski RK, Szeto WY, Pochettino A, Moser GW, Moeller P, Bavaria JE Have hybrid procedures replaced open aortic arch reconstruction in high-risk patients? A comparative study of elective open arch debranching with endovascular stent graft placement and conventional elective open total and distal aortic arch reconstruction. J Thorac Cardiovasc Surg. 2010;140:590-7.

29. Bavaria J, Vallabhajosyula P, Moeller P, Szeto W, Desai N, Pochettino A. Hybrid approaches in arch aneurysms: postoperative and midterm outcomes. $J$ Thorac Cardiovasc Surg. 2013;145:S85-90.

30. Chang Q, Tian C, Wei Y, Qian X, Sun X, Yu C. Hybrid total arch repair without deep hypothermic circulatory arrest for acute type A aortic dissection (R1). J Thorac Cardiovasc Surg. Epub 2012 Nov 8. 